\title{
Analisando (in)formalidades numa comunidade de prática de consultores organizacionais à luz da antropologia lingüística: implicações metodológicas para a pesquisa*
}

\author{
Guilherme Lima Moura**
}

SumÁrio: 1. Introdução; 2. Formalidade-informalidade em eventos comunicativos; 3. E o que seriam as comunidades de prática?; 4. (In)formalidades na CdP Ecco; 5. Conclusão: implicações metodológicas das (in)formalidades para a pesquisa.

Summary: 1 . Introduction; 2 . Formality-informality in communication events; 3 . And what could be communities of practice?; 4. (In)formalities in Ecco CoP; 5. Conclusion: methodological implications of the (in)formalities for the research.

Palavras-chave: comunidades de prática; metodologia, formalidade, antropologia lingüística; Judith Irvine.

KEY WORDs: communities of practice; methodology; formality; linguistic anthropology; Judith Irvine.

Este artigo discute algumas questões sobre formalidade-informalidade a partir da abordagem da antropóloga-lingüista Judith Irvine. O artigo analisa uma comunidade de prática (CdP) de consultores organizacionais, estudada empiricamente por meio da observação participante. O objetivo principal é tratar

\footnotetext{
* Artigo recebido em jan. e aceito em nov. 2007.

** Mestre. Professor assistente da Universidade Federal de Pernambuco (UFPE)/Centro Acadêmico do Agreste (CAA)/Núcleo de Administração e Economia. Pesquisador da Universidade Federal de Pernambuco (UFPE)/Centro de Ciências Sociais Aplicadas (CCSA)/Departamento de Ciências Administrativas (DCA)/Programa de Pós-Graduação em Administração (PPGA)/ Grupo de Estudos em Conhecimento e Consultoria Organizacional (Ecco). Doutorando da Universidade Federal de Pernambuco (UFPE)/Centro de Artes e Comunicação (CAC)/Departamento de Letras/Programa de Pós-Graduação em Letras (PPG). Endereço: Av. Presidente Kennedy, 7770, ap. 102 - Candeias - CEP 54440-480, Jaboatão dos Guararapes, PE, Brasil. E-mail: glmoura@gmail.com.
} 
das dificuldades encontradas na observação, entendidas no texto a partir do que denominamos, com base em Irvine, de implicações metodológicas das "(in)formalidades" à pesquisa. O artigo conclui que os aspectos em que se desdobram tais "(in)formalidades" marcam profundamente o discurso em análise e devem ser notados, não para que se possa esterilizar o discurso desses elementos (como se isso fosse possível e como se tais elementos fossem indesejáveis e/ou extrínsecos), mas para que essas dimensões de análise estendam o foco do código à situação, e desta àquele, enriquecendo o trato social do fenômeno lingüístico e a competência de observação do pesquisador.

\section{Analyzing (in)formalities in an organizational consultants' community of practice in the linguistic anthropology perspective: methodological implications for the research}

This article discusses a few issues on formality-informality based on linguistic anthropologist Judith Irvine's approach. It uses participant observation to analyze an organizational consultants' community of practice (CoP). The main objective is to deal with the difficulties found during the observation, which, based on Irvine, are called the (in)formalities methodological implications for the research. It concludes that the different aspects of such (in)formalities have a deep effect on the discourse under analysis and must be noticed not so much as to sterilize these elements' discourse (as if this was possible and as though those elements were undesirable and/or extrinsic), but so that these analytical dimensions extend the focus of the code to the situation - and vice-versa - enriching the social approach of the linguistic phenomenon and the researcher's observational capabilities.

\section{Introdução}

Este artigo discute algumas questões sobre formalidade-informalidade, tendo como experiência em análise uma comunidade de prática (CdP) de consultores organizacionais, e como referencial interpretativo a abordagem da antropóloga-lingüista Judith Irvine (1984) em seu artigo "Formality and informality in communicative events", com o objetivo principal de tratar das implicações metodológicas desta análise, uma vez que a referida CdP é fenômeno de pesquisa lingüística.

Primeiramente é apresentada a concepção de formalidade-informalidade tratada por Irvine no referido artigo. Em seguida, é construído um conceito de CdP para que, na seqüência, seja apresentada a CdP Ecco como sujeito da análise empírica deste artigo, realizada a partir dos aspectos de formalidade 
descritos na primeira seção. Por fim, temos algumas considerações sobre as implicações metodológicas das (in)formalidades para a pesquisa.

\section{Formalidade-informalidade em eventos comunicativos}

Formalidade e informalidade são conceitos freqüentemente usados na etnografia da comunicação e na sociolingüística, para descrever ocasiões sociais e seu comportamento associado. Mas o que pode ser entendido por formalidade, em termos de características observáveis da interação social? Será um conceito representado em termos de uma dicotomia formal-informal? Ou em um continuum, com graus de formalidade-informalidade? Ou será, ainda, que tal representação é algo mais complexo? Tal pergunta é o fio condutor do artigo "Formality and informality in communicative events" (Irvine, 1984), e sua motivação se deve à necessidade, identificada pela autora, de se desenvolver um vocabulário analítico mais preciso sobre o tema, cujas referências são freqüentemente vagas ou indefinidas. A despreocupação em definir o conceito de formalidade antes de usá-lo supõe que seu significado é claro, quando na verdade é muito variável (Irvine, 1984:211).

A autora estrutura seu texto em quatro seções. Primeiro, uma revisão de literatura sobre o conceito de formalidade. Segundo, uma análise dos conceitos encontrados na revisão. Terceiro, um estudo empírico sobre duas sociedades africanas (wolof e mursi), que são primeiramente comparadas entre si e depois com uma terceira sociedade, os ilongots, do norte das Filipinas. Quarto, uma análise da "utilidade" do conceito de formalidade como um termo de análise em eventos comunicativos.

\section{Revisão de literatura}

O que tem sido entendido por formalidade na literatura antropológica? Uma revisão demonstra basicamente três significados (potencialmente confusos entre si):

v propriedades de um código comunicativo - a formalidade se apresenta no aspecto do código, na estrutura do discurso. Bricker, Gossen e Fox (citados por Irvine, 1984:212) descrevem o discurso formal como marcado por uma estrutura especial (notadamente redundância e paralelismos sintáticos ou se- 
mânticos). Outros autores destacam a predicação do discurso estruturado. Para eles, o estilo formal reduz a variação e a espontaneidade do discurso;

v propriedades de um contexto social no qual o código é usado - a formalidade é entendida como uma forma de descrever as características de uma situação social, não necessariamente no tipo de código usado na situação. Ela é compreendida como o "oposto de intimidade", revelando-se, por exemplo, num tom mais ou menos afetivo, ou sério, ou polido etc. Ervin-Tripp (citado por Irvine, 1984:212) relaciona formalidade à cortesia e à seriedade de cada situação. Rubin (citado por Irvine, 1984:212), por sua vez, define-a como uma variável situacional separada do grau de intimidade e grau de seriedade. Para Labov (citado por Irvine, 1984:212) é a formalidade de um contexto situacional que faz um falante prestar (ou não) atenção ao discurso;

v propriedades da descrição do analista - aqui a formalidade é entendida como a explicitação da descrição observada pelo analista, ou seja, o aspecto técnico da descrição. Diz respeito, basicamente, à declaração do analista das regras que governam o discurso serem maximamente explícitas. Ou seja, a formalidade é percebida nas concepções de sociedade e comportamento que os informantes podem apresentar em declarações verbais explícitas (Irvine, 1984:213).

Essas três formas básicas de se entender formalidade, presentes na literatura antropológica que trata do assunto, estão muito associadas e, portanto, são potencialmente confusas entre si. Por exemplo, quando a formalidade é considerada uma propriedade do contexto social, é comum estendê-la às variedades de código lingüístico usadas nas respectivas situações. É o caso do uso de pronomes pessoais de tratamento, cuja formalidade-informalidade se revela numa mudança de léxico, de código lingüístico (você, senhor etc.), mas reside na situação na qual seu uso é socialmente apropriado ou exigido.

Se por um lado a experiência parece revelar uma proximidade das três concepções descritas, por outro, alguns autores exageram nesse entendimento ao proporem explicitamente a sua fusão, sob o argumento de que (apenas) descrições formais são (mais) apropriadas para discursos que ocorrem em situações formais "cerimonializadas". ${ }^{1}$ Mas Irvine (1984:213) prefere evitar essa, por assim dizer, (con)fusão: "so, with Halliday (1964), I would seek to avoid confusing the technical sense of formality (explicitness of de observer's des-

1 "Ceremonial like formal situations." 
cription) with senses that concern the behavior and conceptual systems of the people described".

Ainda assim, a autora reconhece que algumas inter-relações de diferentes sentidos de formalidade são potencialmente frutíferas. É o caso de Bloch (citado por Irvine, 1984:213), que tem defendido a tese de que a estruturação do código e a formalidade da situação têm relação causal entre si, de modo que um discurso mais estruturado necessariamente demonstra maior cortesia e respeito pelo tradicional (e também, a presença de um possível poder coercitivo).

\section{Análise dos conceitos encontrados na revisão}

Que considerações podem passar pela mente daquele que descreve ocasiões sociais como formais ou informais? É a pergunta que faz Irvine (1984), ao iniciar a análise da revisão de literatura. Para ela, podem ser destacados quatro aspectos de formalidade: o incremento da estrutura de código, a consistência do código, a invocação de identidades de posição e a emergência de um foco central numa situação.

\section{Incremento da estrutura de código}

Adição de regras extras ou convenções aos códigos que organizam o comportamento em um contexto social:

v há vários códigos em ação ao mesmo tempo numa situação social;

v alguns eventos discursivos formalizam diferentes partes dos itens lingüísticos, de modo que não é possível se fazer um simples continuum formalidade versus informalidade.

Por exemplo, entre os wolof há dois diferentes eventos discursivos, woy ("canto de louvor") e xaxaar ("sessões de insulto"), que diferem das conversações ordinárias em suas estruturas e em seus padrões de entonação (entre outros aspectos). Mas tal variação é diferente em cada um dos vários aspectos lingüísticos do discurso realizado na mesma situação. Ou seja, no evento em questão seria impossível dizer que uma forma de discurso é mais ou menos formalizada que a conversação ordinária (ver quadro 1). Davis (1976 citado por Irvine, 1984:214) fez uma análise semelhante entre os Yorubá. 
Quadro 1

Exemplo de variação no incremento da estrutura de código em dois diferentes eventos discursivos wolof

\begin{tabular}{|l|c|c|}
\cline { 2 - 3 } \multicolumn{1}{c|}{} & Woy & Xaxaar \\
\hline Métrica & $<$ Ord. & $>$ Ord. \\
\hline Elocução (ritmo) & $>$ Ord. & $<$ Ord. \\
\hline
\end{tabular}

Legenda: Ord. = "conversação ordinária"; $>=$ "mais estruturado que"; $<=$ "menos estruturado que".

\section{Consistência de código}

Os falantes podem escolher entre várias características do discurso, mas fazem tal escolha coerentemente com a conotação social, para produzirem significância social. Essas características podem ser, por exemplo, a velocidade, o volume, a entonação, entre outros, e são combinadas de modo a indicar uma alta ou baixa hierarquia social do falante. A falta de tal coerência geralmente indica ironia, humor etc.

\section{Invocação de identidades de posição}

Uma identidade social é invocada em uma situação. Ocasiões formais invocam uma identidade pública e não pessoal, parte de uma estrutura formada para ser reconhecida em sociedade. Alguns autores têm relacionado o aspecto de formalidade ao continuum distanciamento-intimidade.

\section{Emergência de um foco central numa situação}

De que maneira ocorre um foco de atenção, no grupo como um todo ou em pequenos grupos? Participantes no foco central têm seu discurso governado por uma organização em tópicos, continuidade e relevância que não ocorre — ou não do mesmo jeito - fora do foco (numa participação descentralizada ou em momentos nos grupos menores que compõem o grande grupo).

\section{"Utilidade" do conceito de formalidade como um termo comparativo}

A grande questão que se destaca a essa altura, tendo-se em vista a pergunta norteadora apresentada no início do artigo de Irvine (1984), é que os vários aspec- 
tos de formalidade tratados ao mesmo tempo em que diferem entre si, não estão totalmente separados. Entretanto, tais aspectos não aumentam ou diminuem juntos, por isso a variação formalidade-informalidade não se dá num simples continuum. Alguns deles dizem respeito a propriedades do código lingüístico, enquanto outros têm mais a ver com a situação social; alguns se concentram sobre o comportamento observável, enquanto outros evocam categorias conceituais de atores sociais. Não obstante, ainda que cada um desses vários aspectos possa ser adotado separadamente, como parte de uma estratégia metodológica de investigação, é importante que sejam consideradas suas inter-relações. Não há, portanto, formalidade ou informalidade, mas (in)formalidades.

Assim, os quatro aspectos propostos pela autora e descritos na seção anterior se apresentam, muitas vezes, imbricados nas situações observadas, ainda que nem sempre a presença de um deles exija a de todos os demais. É o que acontece no momento em que mudanças comportamentais possam redefinir as situações na quais estão inseridos os respectivos atores sociais. Por exemplo, a evocação de certas identidades de posição, como a identificação de um papel relevante para o grupo, pode ampliar a centralização da emergência de foco numa determinada situação, foco que aí se volta para aquele que se revelou portador de posição mais relevante. Esse terceiro aspecto também tende a se relacionar com o segundo, na medida em que o código adotado pelo falante em foco é consistente não apenas com sua identidade pessoal mas, sobretudo, com a categoria da qual faz parte, com sua identidade de posição social. Não obstante esses três aspectos relacionem-se entre si e tendam a afetar o primeiro deles, que por sua vez pode afetar os demais, nem sempre tal relação ocorre. O que significa dizer o incremento na estrutura do código parece ser independente dos outros três aspectos. É o que se observa nos poemas que, mesmo sendo lingüisticamente estruturados, têm, por exemplo, nas inconsistências de código uma contribuição especial para os seus efeitos especiais muito próprios.

Irvine (1984:225) conclui o artigo considerando que esses quatro aspectos de formalidade não compõem propriamente uma ferramenta de análise, dada a sua generalidade, já que a única coisa que todos têm em comum é sua relação com o grau em que ocasião social é sistematicamente organizada. Entretanto, sobressai-se a idéia da complexidade com a qual se apresenta a variação formal-informal nos eventos comunicativos, de modo que o analista precisa saber exatamente do que está falando ao definir alguma situação como formal ou informal. Ou seja, precisa ter em mente de que aspecto fala ao fazer tal observação. E essa é uma preocupação que se estende a outras necessidades de definição em antropologia, como em pesquisa. 


\section{E o que seriam as comunidades de prática?}

A definição de comunidade de prática também tem sido alvo de muitas variações conceituais. E nem mesmo a expressão "comunidade de prática" é unânime para designar o assunto, já que, além dela, alguns autores se referem à "comunidade de aprendizagem", outros ainda utilizam "comunidade de conhecimento", "comunidade de prática social", e ainda "comunidade de saber" (Yi, 2002; Antonello e Ruas, 2002; Valença e Associados, 1995).²

Em meio a tantas perspectivas, Yi (2002:105) destaca em seus escritos o pioneirismo no estudo das CdPs por parte de Lave e Wenger (1991) que, segundo ele, "as definem inicialmente como organizações informais que são naturalmente formadas entre praticantes de dentro e além das fronteiras de organizações formais". Foram esses autores que "cunharam a expressão community of practice para descrever tais organizações informais".

Aqui é adotado o conceito originalmente trabalhado por Lave e Wenger (1991) e posteriormente desenvolvido por Wenger e Snyder (2001). A idéia de CdP é estabelecida basicamente por tais autores a partir de quatro componentes:

v significado que, segundo Figueiredo (2002:4) "traduz a capacidade (e necessidade) que temos para encontrar um sentido para o mundo, aprendemos procurando um sentido para a nossa existência — individual e colectiva - no mundo". Aprendizagem, pensamento e conhecimento são relações entre pessoas em atividade em, e com, um emergido mundo social e culturalmente estruturado. Esse mundo é socialmente constituído. Formas objetivas e sistemas de atividade, por um lado, e entendimentos subjetivos e intersubjetivos dos agentes sobre tais, por outro, mutuamente constituem ambos o mundo e suas formas experimentadas (Lave e Wenger, 1991:51-53);

v prática social que, de acordo com Figueiredo (2002:5) "exprime a vivência partilhada de recursos e perspectivas que mantêm o nosso envolvimento mútuo na ação: aprendemos fazendo". Aprendizagem como participação em CdP's considera integralmente a ação pessoal no mundo. Trata-se de uma visão relacional de indivíduos, suas ações e o seu mundo, típica de uma teoria de prática social (Lave e Wenger, 1991:49);

v comunidade, para Figueiredo (2002:5) "configuração social onde definimos as nossas iniciativas e onde a nossa participação é reconhecida; aprendemos

\footnotetext{
${ }^{2}$ Uma CdP pode ser entendida também como uma "comunidade de fala" (Saville-Troike, 1982).
} 
construindo um sentido de pertença". A participação na prática social sugere um foco muito explícito na pessoa, mas como pessoa-no-mundo, como membro de uma comunidade sociocultural. Tal foco promove a visão de conhecimento como atividade por pessoas específicas em específicas circunstâncias (Lave e Wenger, 1991:53);

- identidade que, para Figueiredo (2002:5), "surge da forma como a aprendizagem transforma quem nós somos e constrói histórias pessoais de quem somos no contexto das nossas comunidades; aprendemos através do processo de construção da nossa própria identidade". A aprendizagem envolve a construção de identidades (Lave e Wenger, 1991:53).

Mais adiante, Wenger e Snyder (2001:10-11) sintetizam as CdP's dessa maneira:

Em síntese, são grupos de pessoas ligadas informalmente pelo conhecimento especializado e compartilhado e pela paixão por um empreendimento conjunto. [...] Inevitavelmente [...] seus participantes compartilham experiências e conhecimento com liberdade e criatividade, incentivando novas abordagens para os problemas.

Para eles, as CdP's “[...] diferem de outras formas de organização, de várias maneiras" (Wenger e Snyder, 2001:13). No quadro 2 constam as diferenças básicas entre elas e os diversos tipos de grupos comumente encontrados nas empresas.

Quadro 2

Diferentes grupos e suas principais características comparadas

\begin{tabular}{|c|c|c|c|c|}
\hline Grupo & $\begin{array}{l}\text { Qual é o } \\
\text { objetivo? }\end{array}$ & $\begin{array}{c}\text { Quem } \\
\text { participa? }\end{array}$ & $\begin{array}{l}\text { O que têm em } \\
\text { comum? }\end{array}$ & $\begin{array}{l}\text { Quanto tempo } \\
\text { duram? }\end{array}$ \\
\hline $\begin{array}{l}\text { Comunidade } \\
\text { de prática }\end{array}$ & $\begin{array}{l}\text { Desenvolver as } \\
\text { competências } \\
\text { dos participantes; } \\
\text { gerar e trocar } \\
\text { conhecimentos }\end{array}$ & $\begin{array}{l}\text { Participantes que } \\
\text { se auto-selecionam } \\
\text { (e integrantes } \\
\text { que avaliam a } \\
\text { adequabilidade } \\
\text { do associado } \\
\text { pretendente) }\end{array}$ & $\begin{array}{l}\text { Paixão, } \\
\text { compromisso e } \\
\text { identificação com } \\
\text { os conhecimentos } \\
\text { especializados do } \\
\text { grupo }\end{array}$ & $\begin{array}{l}\text { Enquanto } \\
\text { houver } \\
\text { interesse em } \\
\text { manter o grupo }\end{array}$ \\
\hline
\end{tabular}




\begin{tabular}{|lllll|}
\hline Grupo & \multicolumn{1}{c}{$\begin{array}{c}\text { Qual é o } \\
\text { objetivo? }\end{array}$} & \multicolumn{1}{c}{$\begin{array}{c}\text { Quem } \\
\text { participa? }\end{array}$} & $\begin{array}{c}\text { O que têm em } \\
\text { comum? }\end{array}$ & $\begin{array}{c}\text { Quanto tempo } \\
\text { duram? }\end{array}$ \\
\hline $\begin{array}{l}\text { Grupo de } \\
\text { trabalho } \\
\text { formal }\end{array}$ & $\begin{array}{l}\text { Desenvolver um } \\
\text { produto ou prestar } \\
\text { um serviço }\end{array}$ & $\begin{array}{l}\text { Qualquer um que se } \\
\text { apresente ao gerente } \\
\text { do grupo }\end{array}$ & $\begin{array}{l}\text { Requisitos do } \\
\text { trabalho e metas } \\
\text { comuns }\end{array}$ & $\begin{array}{l}\text { Até a próxima } \\
\text { reorganização }\end{array}$ \\
$\begin{array}{l}\text { Equipe de } \\
\text { projeto }\end{array}$ & $\begin{array}{l}\text { Realizar } \\
\text { determinada tarefa }\end{array}$ & $\begin{array}{l}\text { Empregados } \\
\text { escolhidos por }\end{array}$ & $\begin{array}{l}\text { As metas e pontos } \\
\text { importantes do }\end{array}$ & $\begin{array}{l}\text { Até o final do } \\
\text { projeto }\end{array}$ \\
& gerentes seniores & projeto & \\
Rede & Colher e transmitir & Amigos e conhecidos & Necessidades & Enquanto as \\
informal & informações & do meio empresarial & mútuas & pessoas tiverem \\
& empresariais & & & $\begin{array}{l}\text { um motivo } \\
\text { para manterem } \\
\text { contato }\end{array}$ \\
\hline
\end{tabular}

Fonte: Wenger e Snyder (2001:15), com adaptações.

Atualmente, é comum que CdPs existam dentro de organizações, mas tanto podem ser encontrados em uma unidade de negócios, como se estender para além das fronteiras da divisão ou mesmo da organização, nesse caso contendo participantes de várias empresas (Wenger e Snyder, 2001:12). São as seguintes as suas principais características:

v quanto à formalização, " ${ }^{3}[. .$.$] a natureza orgânica, espontânea e informal$ das comunidades de prática as torna resistentes à supervisão e interferências. [...] — [elas] se auto-organizam, o que significa que definem suas próprias pautas e sua liderança";

จ quanto aos tipos, “[...] são tão variadas quanto as situações que lhes dão origem";

$\checkmark$ quanto ao porte e quanto à liderança, podem “[...] ter dezenas ou até centenas de indivíduos, mas em geral [possuem] um núcleo de participantes cuja paixão pelo tópico [as] energiza e proporciona liderança social e intelectual";

จ quanto aos processos de inclusão,

a participação numa comunidade de prática é auto-selecionada, ou seja, as pessoas percebem quando, e se devem juntar-se àquela comunidade. Sabem

\footnotetext{
${ }^{3} \mathrm{~A}$ formalização aqui está mais relacionada com o caráter institucional do grupo.
} 
se têm algo a oferecer e se há possibilidade de ganharem alguma coisa. [E os seus integrantes também avaliam] a adequabilidade do associado pretendente para o grupo.

Lave e Wenger (1991:98, tradução nossa) acrescentam ainda que

uma comunidade de prática é uma condição intrínseca para a existência de conhecimento, não apenas porque ela providencia um suporte interpretativo necessário para dar sentido à sua herança. A participação na prática cultural na qual qualquer conhecimento ocorre é um princípio epistemológico de aprendizagem. A estrutura social de sua prática, suas relações de poder, e suas condições para legitimação definem possibilidades para a aprendizagem.

Assim, conforme Gropp (2003:2),

o conceito de prática presente na perspectiva de comunidades de prática, tal como apresentada originalmente por Lave e Wenger, implica um fazer que é determinado por um contexto histórico e social e que por sua vez é responsável pela estrutura e significados que lhe são atribuídos. Assim podemos dizer que uma prática é sempre uma prática social (Wenger, 1995:47) e que as comunidades de prática são os territórios onde o senso comum através do engajamento mútuo permitem elucidar o caracter social e negociado entre o tácito e o explícito nas nossas vidas.

Wenger (1991, 2001 citado por Antonello e Ruas, 2002:4-5) ainda se refere a três aspectos fundamentais que caracterizam a CdP, e a distingue de outros tipos de grupos. O primeiro se refere ao domínio: "[...] tem de haver um assunto sobre o qual a comunidade fala". O segundo se refere às relações entre os participantes: é preciso que os integrantes construam entre si relações, mas também em torno desse assunto, o domínio. Ou seja, de acordo com Antonello e Ruas (2002:4, grifo dos autores), “uma página na web não é uma $C o P$ ou, se houver 60 gestores que nunca se falam, eles não são uma $C o P$, ainda que desempenhem as mesmas funções. [Eles têm] que existir como uma comunidade".

Enfim, o terceiro aspecto se refere à prática: é preciso que, além de um assunto, os integrantes compartilhem uma prática. Eles precisam aprender a fazer juntos; seu interesse reside em compartilhar para aprender a fazer 
melhor a partir da experiência comum. Uma CdP não é simplesmente uma equipe, porque ela se define pelo domínio de interesse e não por um trabalho a realizar, e também não é uma rede informal porque, além de interesses em comum, ela tem uma identidade própria.

\section{4. (In)formalidades na CdP Ecco}

Não obstante as limitações levantadas por Irvine (1984) quanto ao uso dos quatro aspectos de formalidade propostos pela autora como um ferramental analítico útil, é possível fazer algumas reflexões sobre eles, principalmente mantendo-se em vista algumas implicações metodológicas para a pesquisa, que envolve a observação participante em CdPs. Aliás, grupos como esses podem, em princípio, apresentar acentuadas características de cerimonialidade, tais como os eventos discursivos estudados por Irvine (1984) ou os grupos de auto-ajuda, como os alcoólicos anônimos, analisados por Wenger (Lave e Wenger, 1991). Parece, então, que o encontro do fenômeno das CdPs com o viés analítico-empírico sobre formalidade nos eventos discursivos, além de fazer sentido em si mesmo, potencializa enormemente uma reflexão sobre método, ainda mais quando realizada por aquele que está na CdP basicamente para observá-la como um pesquisador lingüista.

Desenrola-se, desse modo, esta seção: primeiro, apresenta-se o fenômeno em análise, a CdP Ecco, descrevendo-se seu funcionamento. Em seguida, tendo em vista alguns eventos comunicativos registrados em caderno de campo numa fase inicial de observações, realiza-se neles uma análise dos quatro aspectos de formalidade já citados. Por fim, direciona-se tal análise para algumas questões metodológicas que atualmente "tiram o meu sono".

A CdP Ecco é uma comunidade de prática de consultores organizacionais criada a partir da iniciativa do Ecco - Grupo de Estudos sobre Conhecimento e Consultoria Organizacional, vinculado ao Propad - Programa de Pós-Graduação em Administração da UFPE (Ecco, 2006). Ela pode ser definida, basicamente, como um espaço para reflexões e discussões sobre a prática da consultoria organizacional, a serem realizadas por seus praticantes, que se encontram periodicamente e em caráter voluntário com tal finalidade. Assim, o Ecco se coloca como provedor de um espaço "institucionalmente neutro", de modo que os consultores organizacionais não vêm à CdP Ecco para ouvir os integrantes do Ecco, mas para se envolverem numa prática discursiva realizada por eles próprios e sobre suas questões de interesse prático. Foi assim que o Ecco propôs publicamente aos consultores da Região Metropolitana do Recife 
a criação da CdP Ecco, cujo início foi em maio de 2006. Sua periodicidade de encontro é mensal - até o momento houve cinco reuniões, de maio a setembro - e a duração média de seus encontros é de três horas. As reuniões ocorridas até agora contaram com a presença de um número variável de participantes, de quatro a 12, dos quais cerca da metade compareceu a todas ou quase todas.

A atual estrutura de funcionamento das reuniões da CdP Ecco conta com as seguintes etapas: apresentação de um caso prático e/ou tema para debate, sob responsabilidade de um dos integrantes da CdP Ecco - a questão da discussão da prática deve estar sempre presente; debate coletivo, mantendose o foco nas perguntas norteadoras - o que o consultor faz em determinadas situações e as questões que o caso levanta; e avaliação coletiva da reunião. Na primeira etapa, o expositor deve, além de apresentar o caso prático, trazer algumas perguntas de seu interesse e que gostaria que fossem "tratadas/respondidas" pelo grupo. E, na segunda etapa, o grupo deve se preocupar em, além de debater e refletir sobre as questões, fazer alguma recomendação ou comentário sobre a prática do expositor, de modo a ajudá-lo (tentando inclusive responder às suas perguntas).

O funcionamento da CdP, portanto, traduz uma cerimonialidade própria do seu grau de estruturação e, como se trata de um grupo que está junto para discutir (e não para construir algum artefato, por exemplo), é particularmente no discurso, e a partir da situação específica, que essa estruturação se revelará.

Quanto à invocação de identidades de posição, a proposta intrínseca da CdP supõe um acesso democrático aos seus recursos, ou seja, evita-se a imposição de lideranças e papéis formais fixados em alguns indivíduos. O fato da CdP Ecco ter sido proposta institucionalmente pelo Ecco é, ao mesmo tempo, uma importante condição de sobrevivência e um obstáculo ao observador que, por ser integrante do Ecco, aparece, aos olhos dos consultores participantes, como uma figura de quem se espera determinações de estratégias de ação, intervenções em impasses e condução do processo. A condição de sobrevivência citada diz respeito ao fato de os consultores já terem vivido anteriormente experiências semelhantes à CdP, que fracassaram por causa da relação ambígua entre discutir, refletir e compartilhar práticas profissionais com concorrentes. Essa questão não está eliminada na CdP Ecco, mas como o Ecco é reconhecido como um grupo que pretende estudar e não praticar a consultoria organizacional, sua condição de provedor de um espaço "neutro" e tradicionalmente voltado ao estudo (a universidade) minimiza a tensão que um espaço profissional pertencente a um dos participantes pode eventualmente criar. Mas é justamente essa condição que faz ressaltar, no observador, a identidade de posição "membro do Ecco", dificultando sua atenção à observação do fenômeno. 
O grupo evoca a liderança "neutra" que vem do Ecco para evitar que algum dos participantes se sobressaia nas decisões. O observador tem distribuído papéis, ficando apenas com o de registro da ata, mas recentemente ao informar ao grupo que iria diminuir sua participação em alguns de seus eventos discursivos (sobretudo nos debates), recebeu com surpresa uma grande resistência por parte dos integrantes. $\mathrm{O}$ registro de algumas falas mostra bem isso. "Olha, é muito cedo pra você fazer esse desmame... a gente está muito no início." "Eu não acredito que o grupo tenha futuro se não houver uma liderança! Não acredito." "Mas... você vai continuar vindo?"

Naturalmente, essa situação amplia a emergência de um foco central numa situação, voltada para o observador. Por um lado, o grupo tende a dar mais atenção à fala do observador, atribuindo-lhe um peso diferenciado; por outro, o grupo requer a intervenção ativa do observador e, para isso, se volta para a fala dele. Essa questão é particularmente forte no início e no final das reuniões, momentos em que se aguarda a abertura e o encerramento "oficiais" do observador (que é visto pelos participantes não como observador, é claro, mas como líder e representante do Ecco).

Não obstante, certa homogeneização das representações sociais na CdP Ecco, uma vez que é justamente essa representação (no caso, profissional) o critério de composição que dá sentido à existência do grupo, é possível observar a consistência de código, que evoca uma terminologia própria do falar de consultor. A referência a palavras-chave como "intervenção", "cliente", "contrato", e frases como "como foi realizado o diagnóstico na empresa para contrapor à fala da direção", "o consultor formalizou relatórios durante o processo" sugerem que os participantes tendem a adotar um vocabulário coerente com a posição social compartilhada por todos: profissional consultor organizacional. Além do interesse óbvio em se discutir a prática de consultoria, é a fala de consultor que legitima a presença do participante e, em alguns momentos, impõe silêncio a algum dos demais. Antes e depois da reunião propriamente dita, observam-se conversações elaboradas em discursos bem diferentes, não só quanto ao tópico discursivo, mas em vários de seus aspectos (tom, velocidade, volume, proximidade física, uso de humor e descontração etc.). Estes são momentos também em que se descentraliza o foco nos subgrupos que naturalmente se estabelecem mais "livremente".

$\mathrm{O}$ incremento da estrutura de código surge meio a reboque dos aspectos já descritos, na medida em que o falante tem certo cuidado na construção de seu discurso. Mas isso fica evidentemente ressaltado no participante que apresenta o caso prático do dia (etapa 1 da estrutura de funcionamento da CdP Ecco). Naturalmente que, tendo o foco central naquela situação em que 
se espera a descrição de um processo prático vivido pelo consultor, e que será debatido em seguida por todos, o falante estrutura seu código lingüístico para ser bem entendido, usando eventualmente de recursos visuais para isso. $\mathrm{O}$ momento apresenta grande formalidade, já que todos aguardavam seu discurso desde o último encontro, momento em que se decidiu quem fará o quê no mês seguinte. A fala, portanto, vem marcada por um prévio pensar e elaborar (inclusive sobre o que não se vai falar), de modo que esse ápice de formalidade se reflete fortemente na estrutura do seu discurso.

\section{Conclusão: implicações metodológicas das (in)formalidades para a pesquisa}

Um pouco na direção do terceiro significado encontrado por Irvine (1984) na revisão de literatura sobre formalidade, "propriedades da descrição do analista", seguem-se algumas reflexões sobre implicações metodológicas das (in)formalidades à pesquisa, em particular ao método de observação participante.

Mesmo não sendo objetos de discussão deste artigo questionamentos epistemológicos mais profundos, é preciso considerar que todo método de pesquisa se desdobra e se apóia em alguma concepção interpretativa. Resumindo, no meu caso, como observador da CdP Ecco, há a suposição de que eu possa participar ativamente naquilo que estou para observar, ao tentar construir uma compreensão possível de significados e sentidos. O observado não é objeto posto à minha investigação. Vou ao encontro daquele para, agindo com ele, esforçar-me por compreender um sentido semântico-pragmático que emergirá daquela situação única, na qual já se inicia a interpretação (longe da idéia de que há, primeiro, uma fase de coleta e, depois, uma fase de análise). E a interpretação é uma recriação que não surge, senão, pela via da teoria que a descortina. Portanto, não está em questão alguma exigência de neutralidade na experiência de pesquisa, tampouco me incomoda a percepção de minha influência no fenômeno que observo. Assume a condição de integrante da comunidade como condição natural do processo de investigação e reflexão, que ocorre na relação com os sujeitos da pesquisa. ${ }^{4}$

O que incomoda, então? Em verdade, reconheço a influência, os aspectos de formalidade presentes nas reuniões da CdP têm condicionado o grupo

\footnotetext{
${ }^{4}$ Nas palavras de Saville-Troike, é preciso "ser um membro funcional da comunidade" (1982: 1).
} 
a me manter mais ativo no processo do que o necessário, mesmo ciente de que minha participação se concentre mais no evento discursivo e em seus desdobramentos, e menos na condução da reunião e no tema discutido. Minha suposição é de que a formalidade, em suas quatro dimensões, tem sido um obstáculo a uma observação mais eficaz, que me faz crer que este é um tema necessário para as reflexões sobre esse tipo de método de coleta de dados empíricos.

O grau de (in)formalidades da situação em que me encontro teria, desse modo, relação diretamente proporcional com a dificuldade de observação, no caso em questão agravada pela relação institucional da CdP Ecco com o Ecco. É o que ocorre, por exemplo, com a invocação de identidades de posição, que ressalta meu papel de observador, insistentemente reconhecido como figura de liderança; e amplia a emergência de um foco central numa situação em que me vejo convocado a intervir de modo diferenciado.

Além de obstáculo à ação de observar, a formalidade se revela também no incremento da estrutura de código dos falantes e na sua consistência de código, representadores de suas posições socioprofissionais. Se tal postura é, por um lado, reveladora de uma estratégia discursiva que, por si só, já é interessante questão de pesquisa, por outro, pode sugerir estratégias de proteção de face e alguma artificialidade de expressão, que impedem uma leitura mais profunda do fenômeno.

Tais aspectos, portanto, marcam profundamente o discurso em análise e devem ser notados por mim como pesquisador, não para que se possa esterilizar o discurso desses elementos (como se isso fosse possível e como se tais elementos fossem indesejáveis e/ou extrínsecos), mas para que essas dimensões de análise estendam o foco do código à situação, e desta àquele, enriquecendo o trato social do fenômeno lingüístico e a minha competência de observação como pesquisador.

\section{Referências bibliográficas}

ANTONELLO, C. S.; RUAS, R. Formação gerencial: pós-graduação lato sensu e o papel das comunidades de prática. In: ENCONTRO NACIONAL DOS PROGRAMAS DE PÓS-GRADUAÇÃO EM ADMINISTRAÇÃO, 26., 2002, Salvador. Anais eletrônicos... Salvador: Anpad, 2002.

ECCO (GRUPO DE PESQUISAS SOBRE CONHECIMENTO E CONSULTORIA ORGANIZACIONAL). Disponível em: <www.ufpe.br/ecco>. Acesso em: 15 out. 2006. 
FIGUEIREDO, António Dias de. Redes e educação: a surpreendente riqueza de um conceito. In: Redes de aprendizagem, redes de conhecimento. Lisboa: Conselho Nacional de Educação, Ministério da Educação, 2002.

GROPP, B. M. C. De “cascão a lagartixa": uma abordagem etnográfica focada na perspectiva de comunidades de prática em aprendizagem organizacional. In: ENCONTRO NACIONAL DOS PROGRAMAS DE PÓS-GRADUAÇÃO EM ADMINISTRAÇÃO, 27., 2003, Atibaia. Anais eletrônicos... Atibaia: Anpad, 2003.

IRVINE, Judith T. Formality and informality in communicative events. In: BAUGH, J.; SHERZER, J. (Eds.). Language in use. Readings in sociolinguistics. New Jersey: Prentice Hall, 1984. p. 211-228.

LAVE, J.; WENGER, E. Situated learning: legitimate peripheral participation. Cambridge: Cambridge University Press, 1991.

SAVILLE-TROIKE, M. The ethnography of communication (tradução livre do capítulo 4), 1982.

VALENÇA E ASSOCIADOS. Consultores em ação: uma pesquisa sobre aprendizagem organizacional. Recife: Bagaço, 1995.

WENGER, E. C.; SNYDER, W. M. Comunidades de prática: a fronteira organizacional. Aprendizagem organizacional. Harvard Business Review, Rio de Janeiro: Campus, 2001.

YI, J. Q. Facilitating learning and knowledge creation in community of practice: a case study in a corporate learning environment. In: COAKES, E.; WILLIS, D.; CLARKE, S. (Eds.). Knowledge management in the sociotechnical world: the grafitti continues. London: Springer-Verlag, 2002. 